\title{
Carbon nanotubes with controlled length - preparation, characterization and their cytocompatibility effects
}

\author{
Krzysztof Cendrowski ${ }^{1 *}$, Magdalena Jedrzejczak-Silicka, ${ }^{2, *}$ \\ ${ }^{1}$ West Pomeranian University of Technology, Szczecin, Nanomaterials Physicochemistry Department, Faculty of Technology \\ and Chemical Engineering, Piastow Avenue 45, Szczecin 70-311, Poland \\ ${ }^{2}$ West Pomeranian University of Technology, Szczecin, Laboratory of Molecular Cytogenetic, Klemensa Janickiego 29 , \\ Szczecin 71-270, Poland \\ "Corresponding authors: e-mail: kcendrowski@zut.edu.pl,mjedrzejczak@zut.edu.pl
}

\begin{abstract}
Multiwalled carbon nanotubes (MWCNTs) have attracted huge attention due to their multifunctionality. Their unique properties allows for covalent and noncovalent modifications. The most simple method for functionalization of carbon nanotubes is their decoration with the oxygen containing moieties which can be further simultaneously functionalized for design of new class carriers for targeting and imaging. Here, we present methodology for chopping nanotubes, characterization of MWCNTs, the effect of size on the biocompatibility in culture of L929 mouse fibroblasts using WST-1, LDH and apoptosis assays. The analysis provides the optimal carbon nanotubes length and concentration which can be used for functionalization in order to minimize the effect of the secondary agglomeration when interacting with cells.
\end{abstract}

Keywords: Multiwalled carbon nanotubes, cutting carbon nanotubes, size effect, mitochondrial activity, biocompatibility, apoptosis, necrosis.

\section{INTRODUCTION}

Since 1991, when Sumio Iijima has published a groundbreaking paper on observation of carbon nanotubes ${ }^{1}$, application of single and multiwalled carbon nanotubes (MWCNTs) in medicine science has become one of the most exciting ideas ${ }^{2,3}$. Lately, the carbon nanotubes issue became more attractive due to detailed research and developing new methods of synthesis of different carbon nanotube structures ${ }^{4,5}$. The wide scope of research on the application of carbon nanotubes has resulted in their potential use as carriers of biologically active cargo including drugs, genes or dyes ${ }^{6,7}$, and in the anticancer therapy ${ }^{8}$. Another major area of interest is the application of carbon nanotubes as a supplement for polymer composites for medical use?.

Before the nanomaterials are applied into or with living organism a systematic study is required on biocompatibility of nanotubes with a defined size of particles. Furthermore, the interaction of the nanotubes with the mammalian cells also requires detailed analysis ${ }^{10}$. Progress in CNT research in recent years resulted in many in vitro and in vivo research, by different groups and under different experimental conditions ${ }^{11,12}$. Review of Suh et al. ${ }^{13}$ presented that materials with various length and diameter obtained from different routes of synthesis evoke toxicity at different level. The toxicity of the nanotubes depends mostly on functionalization, concentration and length of the nanostructure ${ }^{14}$. Due to a strong correlation of the chemical and physical nature of the carbon nanomaterial, many efforts have been focused on sample preparation and bio-functionalization steps with their negative effect on the cells viability ${ }^{15}$. Kagan et al. ${ }^{16}$ studied relationship between degradation of carbon nanotubes and the lungs' inflammatory response to the particles. Presented results show novel route of bioenzymatic degradation of carbon nanotubes.

Presently known methods on cutting carbon nanotubes can be divided into two groups: chemical ${ }^{17-20}$ and mechanical cutting ${ }^{21,22}$. In the chemical methods of carbon nanotubes cleavage, highly reactive defect sites are formed by an oxidant along the length of the nanotubes. Commonly, the process relies on liquid phase oxidation with concentrated acids (often a mixture of nitric and sulphuric acid), sonication in the presence of a atactic poly (methyl methacrylate) (PMMA) solution in monochlorobenzene ${ }^{24}$, and fluorination followed by the removal of fluorine groups via heat treatment ${ }^{19}$.

The mechanical cutting of carbon nanotubes is based on ball milling in reactive atmospheres or grinding with diamond particles ${ }^{23}$. Although these methods are capable of cutting nanotubes, they are time-consuming, as mechanical grinding of materials, particularly carbon nanotubes, to nanometre scale may take days to complete.

The latest report on length control of carbon nanotubes highlights mostly methods based on cutting nanotubes by catalytic hydrogenation of carbon, in which metal particles (like cobalt or nickel) cut sp2 hybridized carbon atoms along nanotubes. Another reported method of cutting nanotubes uses thermal oxidizing effect. In this method, carbon nanotubes are cleaved by series of short-term thermal air exposures. However, shortterm thermal oxidative exposure studies have shown that a single defect on the surface of carbon nanotube can lead to gasification of the entire graphitic wall ${ }^{25}$. For single walled carbon nanotubes, thermal oxidation has been used as a mean of defect location, but it also resulted in shortening of individual carbon nanotubes ${ }^{\mathbf{2 6}}$.

Presented study is focused on the multiwalled carbon nanotubes grown by chemical vapour deposition (CVD) due to their multifunctionality and potential biomedical applications. The advantage of the proposed chopping technique is its simplicity and simultaneous introduction of the functional groups which can be further functionalize, thus the aim of presented study were detailed analyses of the influence of length of carbon nanotubes on mitochondrial activity (WST-1 assay), membrane integrity (LDH assay) and apoptosis/necrosis of mouse L929 fibroblasts (Figure 1). 


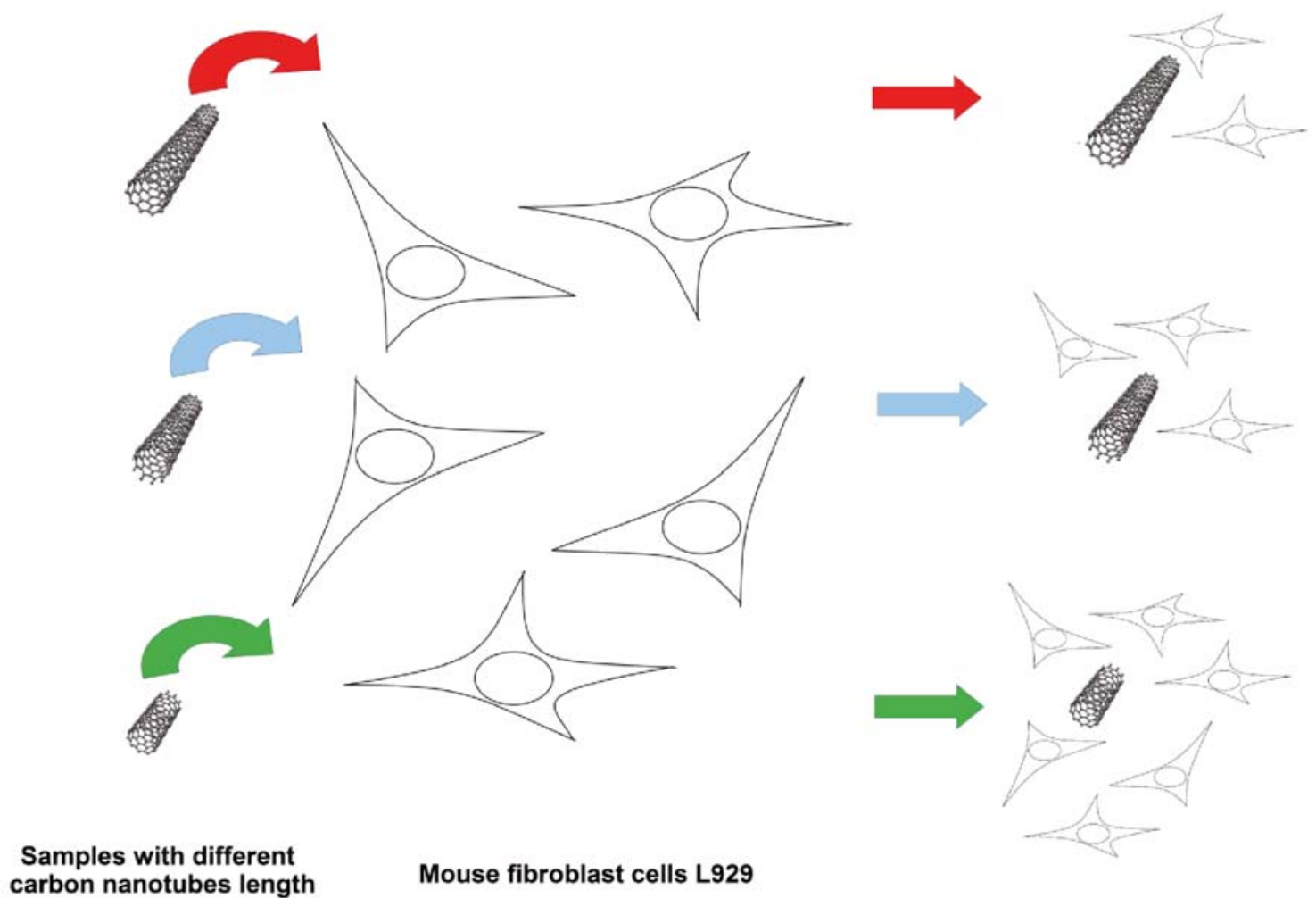

Figure 1. Schematic representation of the experiment performed in L929 cell cultures

\section{EXPERIMENTAL}

\section{Material}

Carbon nanotubes used in our study were purchased from Shenzhen Nanotech Port Co. (Shenzhen, China). Nitric and sulphuric acids were provided from $\mathrm{POCH}$ S.A. (Poland, Gliwice).

\section{Chopping of multiwalled carbon nanotubes (MWCNTs)}

The reduction of carbon nanotubes length was attained by sonication in mixture of $\mathrm{H}_{2} \mathrm{SO}_{4}$ and $\mathrm{HNO}_{3}(3: 1$ $\mathrm{v} / \mathrm{v})$. MWCNTs were sonicated for 4,8 and 12 hours. The control sample was stirred in the above-described acid mixture for $4 \mathrm{~h}$ in the room temperature to induce the presence of functional groups without tubes length modification. Then the samples were collected through multiple washing and filtration followed by centrifugation in order to remove acids.

\section{Characterization techniques}

TEM images were collected using an FEI Tecnai $\mathrm{G}^{2}$ F20 S Twin with an accelerating voltage of $200 \mathrm{kV}$. The strong acid treatment is well known not only to chop the CNTs but also to generate carboxylic and hydroxylic functional groups on the wall surface. Raman spectroscopy (RENISHAW IN VIA Raman Microscope Spectrometer) was employed to evaluate the introduction of defects $(\lambda=785 \mathrm{~nm})$ and Infrared analysis was applied to detect functional groups (IR Nicolet 6700 -THERMOSCIENTIFIC). Additionally, the same amount of each samples was incinerated in thermoweight in order to determine the purity and the content of functional groups. Thermogravimetric measurements were performed with a thermoweight TA Instruments DTA-Q600 SDT.

\section{Cell culture condition and experimental treatment}

L929 mouse skin fibroblasts were cultured in 96-well plates at the density of $7.4 \times 10^{3}$ per well in standard cell culture conditions: at $37^{\circ} \mathrm{C}, 5 \% \mathrm{CO}_{2}, 95 \%$ humidity. DMEM culture medium (Gibco, Langley, OK, USA) was supplemented with $10 \%$ of foetal bovine serum (Gibco, Langley, OK, USA), 2 mM L-glutamine (Sigma-Aldrich, St. Louis, MO, USA) and $0.4 \%$ streptomycin/penicillin (Sigma-Aldrich, St. Louis, MO, USA). 24 hours after cells seeding, the nanotubes were added to the cell culture to obtain final concentrations of $0.0,3.125,6.25$, $12.5,25.0,50.0,100.0 \mu \mathrm{gml}^{-1}$, respectively, and were incubated for $48 \mathrm{~h}$.

\section{Cell morphology}

The L929 cells were incubated with the MWCNTs with different length at different concentrations for $48 \mathrm{~h}$. After exposure period, L929 cell morphology was observed by phase contrast inverted Nikon TS-100 microscope (NIS Elements F Package, camera Nikon DS-Fi1, Nikon, Melville, NY, USA) at $400 \mathrm{x}$ magnification.

\section{The biocompatibility study}

The biocompatibility of carbon nanotubes of different lengths were tested using the WST-1 Cell Proliferation Reagent (Roche Applied Science, Mennheim, Germany) and the LDH CytoTox $96{ }^{\circledR}$ Non-Radioactive Cytotoxicity Assay (Promega, Madison, WI, USA). The WST-1 Cell Viability and Proliferation Assay are based on the reduction of water soluble tetrazolium salts to red formazan by oxidoreductase enzymes from metabolically active cells. After 48-hour exposure period, the WST-1 reagent was added to L929 cultures and was incubated for 45 minutes at $37^{\circ} \mathrm{C}$. After incubation, the absorbance was recorded at $450 \mathrm{~nm}$ (with a reference wavelength at 630 $\mathrm{nm}$ ), according to the manufacturer's instructions using 
Sunrise Absorbance Reader (Sunrise, Tecan, Männedorf, Switzerland). Cells maintained in a complete DMEM medium without adding the tested samples were used as a control. The interaction between nanomaterials and WST-1 reagents was also determined. All the experiments were conducted in triplicate.

The LDH CytoTox $96^{\circledR}$ Non-Radioactive Cytotoxicity Assay measures lactate dehydrogenase (LDH) enzyme that is released upon cell lysis (loss of cellular membrane integrity). For the maximum LDH release $10 \mathrm{x}$ lysis solution (Promega, Madison, WI, USA) was added and incubated at $37^{\circ} \mathrm{C}$ for $45 \mathrm{~min}$. After incubation plates were centrifuged at $240 \mathrm{x}$ g for $4 \mathrm{~min}$. Supernatant were mix with Substrate Mix (Promega, Madison, WI, USA) and incubated for $30 \mathrm{~min}$ at room temperature (light protected). To stop reaction Stop Solution (Promega, Madison, WI, USA) was added and absorbance was measured at $490 \mathrm{~nm}$ using a microplate spectrophotometer (Sunrise, Tecan, Männedorf, Switzerland). To determine potential interaction between NPs and assay components the additional experiment was performed using different CNTs concentrations in cell culture medium in the absence of cells. All the experiments were conducted in triplicate.

\section{Annexin V/propidium iodide staining for cell death analysis}

The mouse L929 cells were seeding into a 24-well plates at a density of $5 \times 10^{4}$ per well. Cell cultures were maintained at $37^{\circ} \mathrm{C}, 5 \% \mathrm{CO}_{2}$, humidity $95 \%$ in DMEM medium as described above. After the period of $24 \mathrm{~h}$ different length nanotubes at different final 0.0, 3.125, $6.25,12.5,25.0,50.0,100.0 \mu \mathrm{gml}^{-1}$ concentrations were added to the cell cultures and were incubated for $24 \mathrm{~h}$. After incubation cells were harvested using trypsin-EDTA solution (Sigma-Aldrich, St. Louis, MO, USA) and stained using the Tali ${ }^{\mathrm{TM}}$ Apoptosis Kit (Invitrogen, Carlsbad, CA, USA) according to manufacturer's protocol. The measurement was performed using Tali ${ }^{\mathrm{TM}}$ Image-Based
Cytometer (Invitrogen, Carlsbad, CA, USA). All the experiments were conducted in duplicate.

\section{Statistical analysis}

The data obtained from presented experiments were expressed as mean \pm standard deviation. The data for WST-1 test and LDH assay were performed using Student's test for unpaired data. The $p$-values-0.05 was considered significant. For data form Annexin V/propidium iodide staining for cell death analysis the Wilcoxon signed-rank test were used. Analysis were performed using the STATISTICA 8.0 (StatSoft Inc., Tulsa, OK, USA) the statistical software.

\section{RESULTS AND DISCUSSION}

Morphology of the chopped carbon nanotubes and the control sample was analyzed by transmission electron and atomic force microscopes, and the representative images are depicted in Figure 2. TEM reveals that sonication resulted in shortened carbon nanotube lengths. CNT lengths after 4 hours of sonication was $0.25-1.0$ $\mu \mathrm{m}$, but after 8 hours $0.25-0.8 \mu \mathrm{m}$. The shortest carbon nanotubes, with length up to $0.4 \mu \mathrm{m}$ required 12 hours of treatment. The control and pristine (without acid modification) sample exhibited the similar length, ranging from $0.2 \mu \mathrm{m}$ to $5.0 \mu \mathrm{m}$. There was not notice any changes in carbon nanotubes diameter during acid treatment in respect to the pristine carbon nanotubes. The AFM has fully confirmed these observations (right panel of Figure 2). The size of the carbon nanotubes has been estimated basing on numerous TEM and AFM images (at least 100 species from each technique per sample). Histograms with the nanotubes length distribution are shown in the Figure 2.

In the FT-IR spectra of control and chopped MWCNTs, characteristic peaks of $\mathrm{COOH}$ functionality at $1130 \mathrm{~cm}^{-1}$ and $3720 \mathrm{~cm}^{-1}$ are present. The absorption peak with very strong intensity located at $1130 \mathrm{~cm}^{-1}$ is attributed

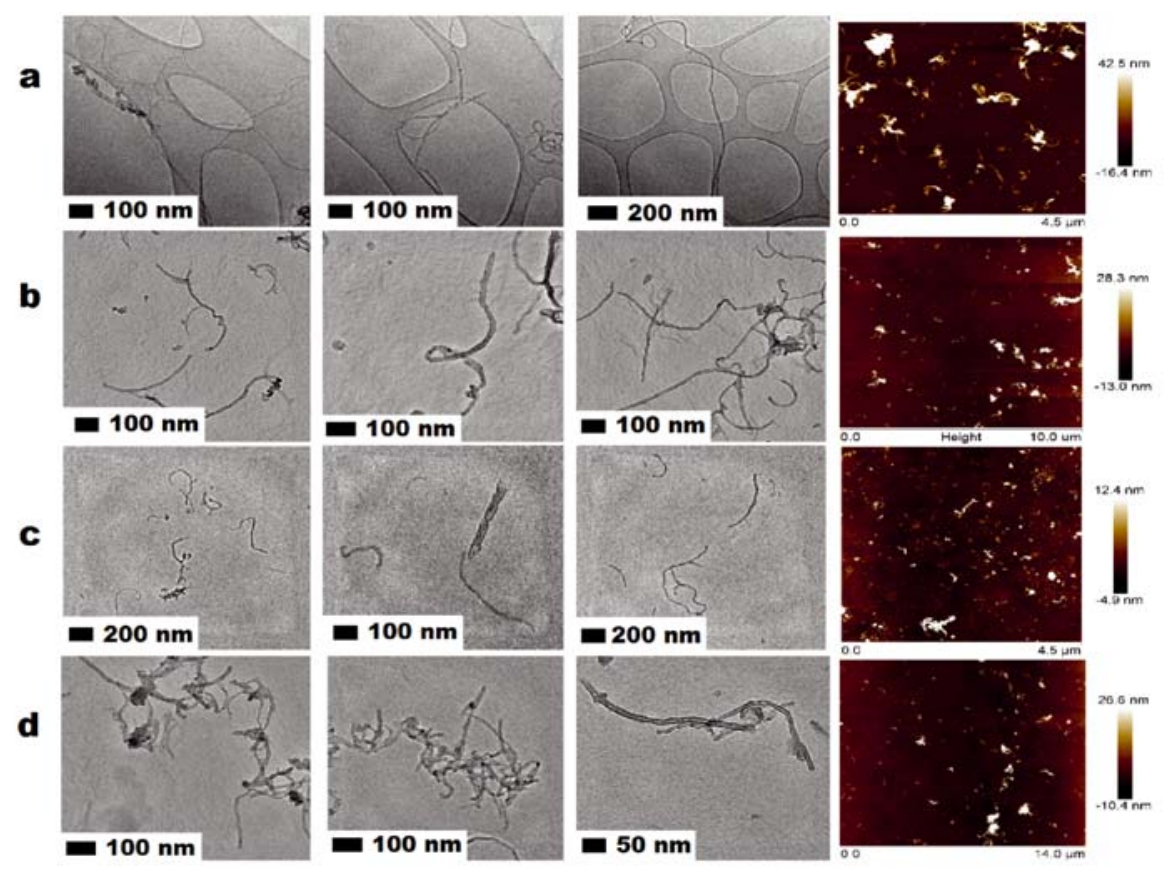

Figure 2. TEM/AFM images of pristine carbon nanotubes (a), chopped during 4 (b), 8 (c) and 12-h (d) sonication in mixture of acids 
to the $\mathrm{C}-\mathrm{O}$ stretching mode quinone group. The peaks at 1515,1670 , and 1620 correspond to $\mathrm{C}=\mathrm{O}$ (from the ester), which is attached to aromatic groups. The peaks at 1410,2761 and $3105 \mathrm{~cm}^{-1}$ are related to sulfate groups of $-\mathrm{CH}_{2}$ - bonds. The band at 1208 and $3637 \mathrm{~cm}^{-1}$ come from hydroxyl group $\mathrm{O}-\mathrm{H}$. Therefore, one can clearly state that the functional groups are efficiently grafted onto the nanotubes in our samples. Additionally, the Figure 3 shows that the starting pristine CNTs do not show clear modes in the analyzed spectral range. The only peak comes from -OH groups originating from the atmosphere.

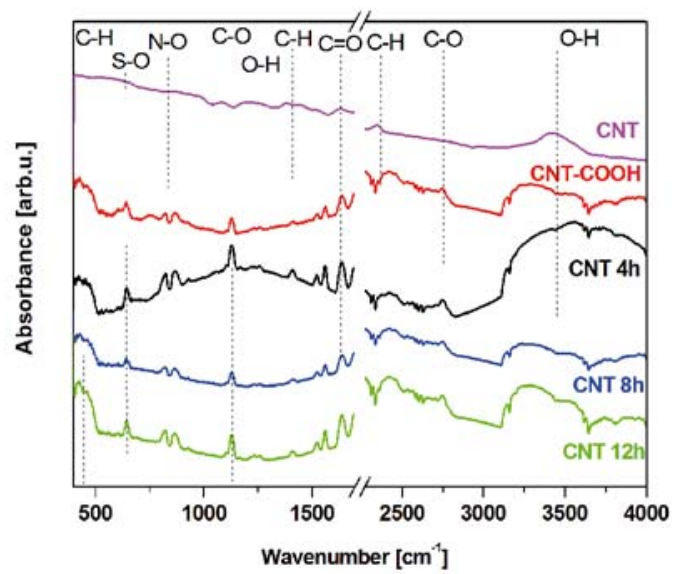

Figure 3. FT-IR spectra of the pristine carbon nanotubes (purple plot), control sample after acids functionalization (red plot), and carbon nanotubes chopped during 4 (black plot), 8 (blue plot) and 12-h (green plot) sonication

Each sample was also explored in detail via Raman spectroscopy, which is a powerful tool to study multiwalled CNTs via the tangential modes, i.e. the $\mathrm{G}$ mode (derived from the graphite-like in-plane mode) and the disorder-induced D band. Since the $G$ mode arises from sp2 $\mathrm{C}$ crystalline structures and the $\mathrm{D}$ mode from defects and amorphous carbon, the G/D ratio is often used as a measure of the sample quality and the level of functionalization ${ }^{26}$. Increased concentration of the functional groups will intensify the D mode. Figure $4 \mathrm{a}$ shows $D$ and $G$ lines for the pristine, control sample and real samples produced during 4, 8 and 12-hour sonication. With the elongation of ultrasounds treatment $\mathrm{G} / \mathrm{D}$, peaks ratio clearly decreases, what is also presented in Figure 4b. This relationship is closely related to the amount of functional groups and defects in the crystal structure of MWCNTs. The following trend is observed: with the increases of sonication time, the $G / D$ ratio decreases suggesting more pronounced $\mathrm{D}$ mode and hence more functional groups induced in the respective samples. However this effect is the most significant in the sample sonicated for $12 \mathrm{~h}$, what can be related to the higher number of defected tubes formed upon the long ultrasound treatment. This observation required detailed high resolution TEM investigation which has confirmed the analysis of Raman response of the species (data not shown here).

The DTA analysis of CNTs presents good indication of the functionality. The burning temperature up to $300^{\circ} \mathrm{C}$ is related to the combustion of the functional groups and the range between $300^{\circ} \mathrm{C}$ and $450^{\circ} \mathrm{C}$ is usually assigned
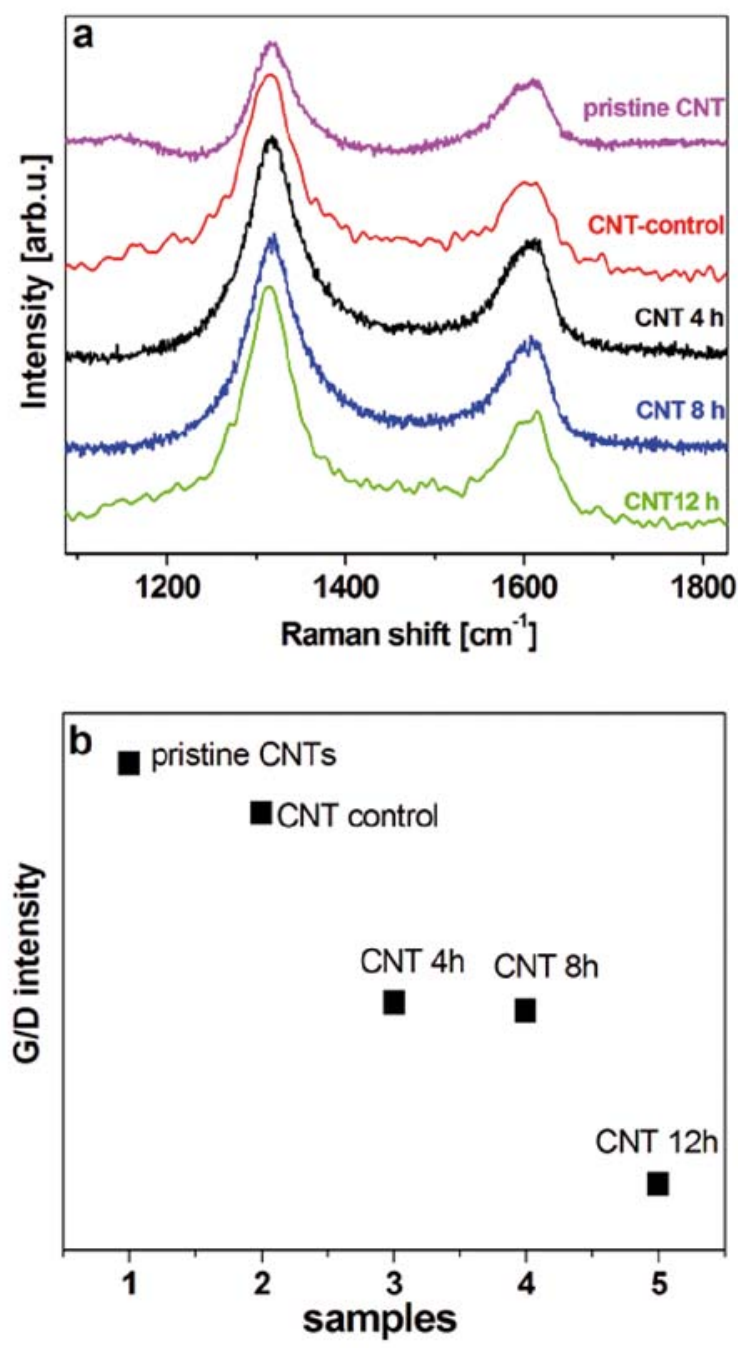

Figure 4. Raman spectra in the range of $\mathrm{D}$ and $\mathrm{G}$ lines for the pristine and control sample and samples produced for 4,8 and $12 \mathrm{~h}$ of sonication (a). Diagram of the ratio intensity $G / D$ mode in the samples (b)

to thermal decomposition of amorphous species. Weight loss above $500^{\circ} \mathrm{C}$ is attributed to the combustion of carbon nanotubes. In DTA of our samples (Figure 5), the pristine material does not exhibit any weight loss in the temperature up to $\sim 500^{\circ} \mathrm{C}$, what can be the evidence of high purity of the starting material. Furthermore, the control sample obtained during mixing of pristine MWCNTs in acids resulted in the generation of functional groups (very small but broad region, assigned as I, in DTA curve). The acid treatment was very gentle and did not produce amorphous carbon (lack of the band in the range between 300 and $450^{\circ} \mathrm{C}$ - region II). The samples sonicated in the acids exhibited increasing band related to the combustion of functional groups and amorphous carbon. The band II, attributed to burning of the amorphous carbon, is the highest in the sample sonicated for $12 \mathrm{~h}$. This observation explains the highest intensity of D mode in Raman spectrum of this sample among all chopped MWCNTs.

Different method of chopping carbon nanotubes were reported in several others publication in the last decades. Ziegler et al. ${ }^{27}$ described procedure of shortening of carbon nanotubes by the carbon fluorination technique strategy. The process involves fluorination of the $\mathrm{C}=\mathrm{C}$ bond to the $\mathrm{C} 2 \mathrm{~F}$ which creates sidewall vacancies. The- 


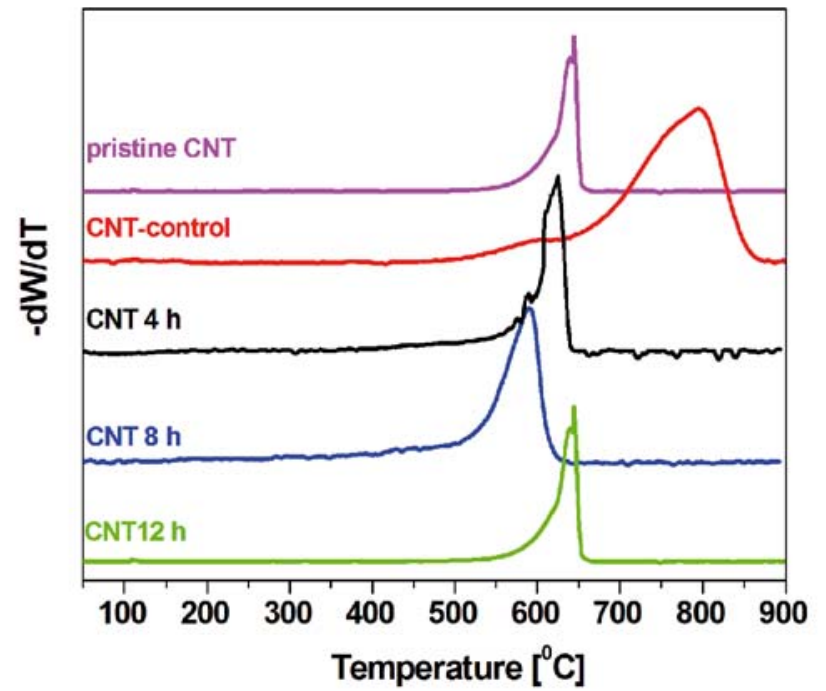

Figure 5. DTA curves of the pristine carbon nanotubes (purple plot), control sample after acids functionalization (red plot), and carbon nanotubes chopped during 4 (black plot), 8 (blue plot) and 12-h (green plot) sonication

se vacancies are exploited through the use of a strong oxidizing solution like Caro's acid solutions ${ }^{27}$. In 2008 Wang et al. reported technique of cutting carbon nanotubes through the thermal oxidation enhanced through the deposition silver nanoparticles on the side wall of the nanotubes. Due to the heat accumulation in the deposited nanoparticles carbon nanotubes, are chopped ${ }^{28}$. Method proposed by Ziegler ${ }^{27}$ was modified technique proposed by Wang et al. ${ }^{28}$ in 2006. In this technique carbon nanotubes with deposited nickel particles are heated in elevated temperature ${ }^{20}$. Hennrich et al. ${ }^{29} \mathrm{pu}-$ blished study on the chopping of single-walled carbon nanotubes. In their experiment SWCNT were chopped by sonication with high power tip sonicator in the sodium cholate/D2O solution ${ }^{29}$. In 2010 Cheng et al. ${ }^{30}$, published detailed study on the sonochemical methods effect on the SWCNT properties.

In all above-cited reports it is shown that there is many ways to control the carbon nanotubes length. However, carbon nanotubes used in those publications differ from each other in terms of carbon nanotubes source, sidewalls number, purity and defects concentrations in nanotubes sidewalls. The advantage of the proposed in our study, the sonochemical chopping technique is its simplicity. Here, the simultaneous cutting of the nanotubes and introduction of the functional groups, that increase nanomaterials dispersion and biocompatibility, occurred. $\mathrm{Krik}^{27}$ and Wang ${ }^{28}$ techniques of cutting carbon nanotubes requires the introduction of metal particles that can decrease the purity of the investigated sample and influence the cytotoxicity of the carbon nanotubes.

The optical microscopy characterization of untreated L929 cells and cells incubated with multiwalled carbon nanotubes are presented in the Figure 6. L929 cells incubated with MWCNT-12 h (up to $400 \mathrm{~nm}$ length) at concentration ranging from 3.125-100.0 $\mu \mathrm{gml}^{-1}$ demonstrated normal morphology even exposure of cells to the highest concentrations $\left(50.0-100.0 \mu \mathrm{gml}^{-1}\right)$. During the exposure of fibroblasts to MWCNTs-12 h cells did not change shape and did not show tendency to form clusters. The suspensions of carbon nanotubes chopped by ultrasounds for $12 \mathrm{~h}$ at concentrations from $50.0 \mu \mathrm{gml}^{-1}$ to $100.0 \mu \mathrm{gml}^{-1}$ were not stable as a hydrocolloid and many agglomerates were noticed. The black and brownish particles were observed most likely around the cells associated with the cellular membranes. The concentration of carbon nanotubes up to the $25.0 \mu \mathrm{gml}^{-1}$ shows lower tendency of formation free standing agglomerates
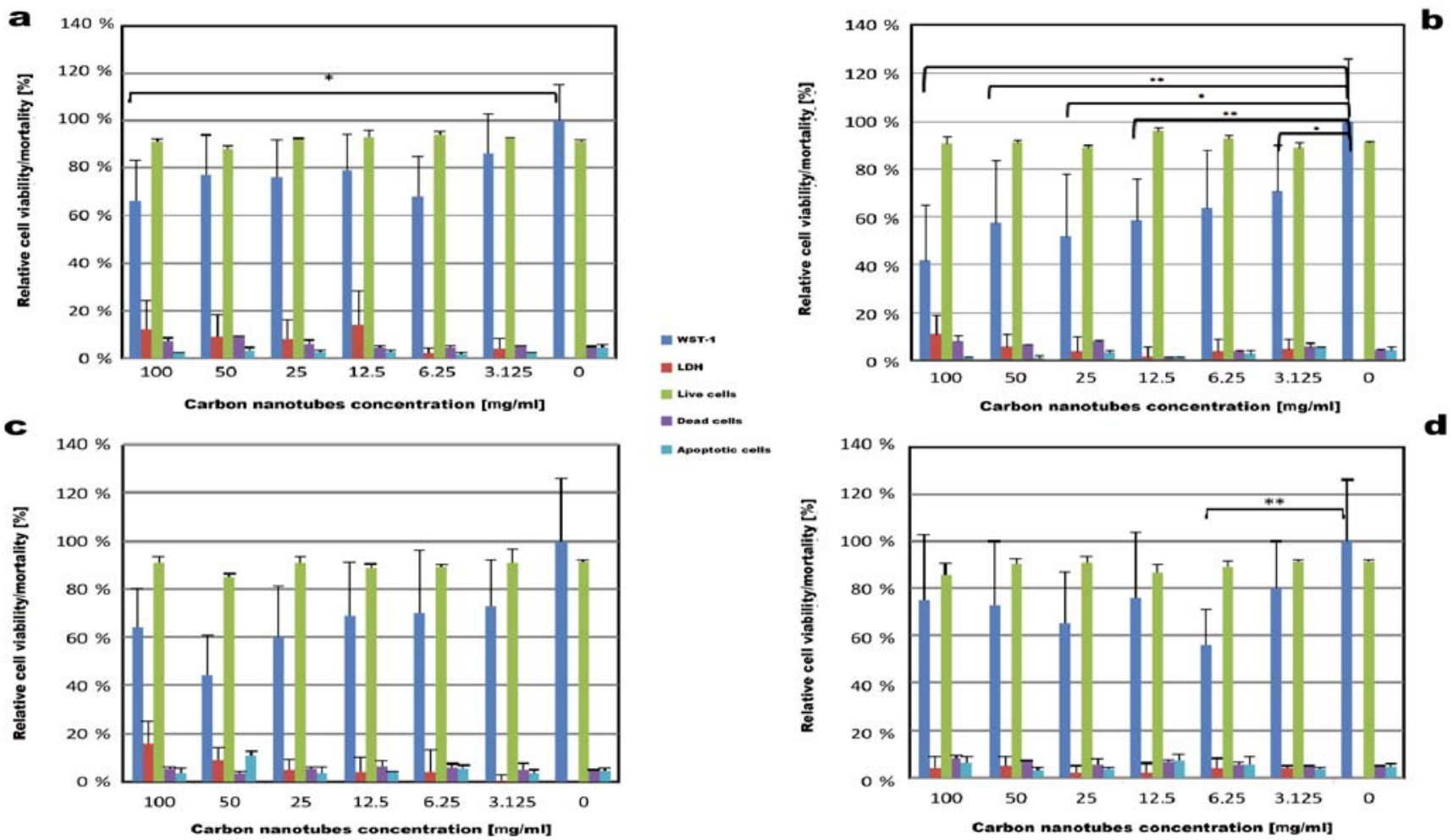

Figure 6. Optical microscope images of L929 mouse fibroblasts after 24-hour incubation with carbon nanotubes: control sample after acids functionlisation (a); chopped during 4 (b), 8 (c) and 12-h (d) sonication. Scale bar: $50 \mu \mathrm{m}$ 
Table 1. Cell culture morphology and metabolic features during $48 \mathrm{~h}$ incubation with MWCNTs at different concentrations

\begin{tabular}{|c|c|c|c|c|c|c|c|c|c|c|c|c|c|c|c|c|c|c|c|c|c|c|c|c|}
\hline \multirow{2}{*}{$\begin{array}{l}\text { Cell culture } \\
\text { morphology } \\
\text { and metabolic } \\
\text { features }\end{array}$} & \multicolumn{6}{|c|}{$\begin{array}{l}\text { CNTs chopped for } 12 \mathrm{~h}[\mu \mathrm{g} / \mathrm{mL}] \\
\text { up to } 400 \mathrm{~nm} \text { length }\end{array}$} & \multicolumn{6}{|c|}{$\begin{array}{l}\text { CNTs chopped for } 8 \mathrm{~h}[\mu \mathrm{g} / \mathrm{mL}] \\
250-800 \mathrm{~nm} \text { length }\end{array}$} & \multicolumn{6}{|c|}{$\begin{array}{l}\text { CNTs chopped for } 4 \mathrm{~h}[\mu \mathrm{g} / \mathrm{mL}] \\
250-1000 \mathrm{~nm} \text { length }\end{array}$} & \multicolumn{6}{|c|}{$\begin{array}{l}\text { CNTs control sample }[\mu \mathrm{g} / \mathrm{mL}] \\
200-5000 \mathrm{~nm} \text { length }\end{array}$} \\
\hline & 100 & 50 & 25 & 12.5 & 6.25 & 3.125 & 100 & 50 & 25 & 12.5 & 6.25 & 3.125 & 100 & 50 & 25 & 12.5 & 6.25 & 3.125 & 100 & 50 & 25 & 12.5 & 6.25 & 3.125 \\
\hline $\begin{array}{c}\text { CNTs } \\
\text { agglomeration }\end{array}$ & +++ & ++ & + & - & - & - & +++ & +++ & - & - & - & - & +++ & + & + & - & - & - & +++ & ++ & + & + & - & - \\
\hline $\begin{array}{l}\text { Cellular } \\
\text { uptake of } \\
\text { CTNs }\end{array}$ & + & ++ & ++ & +++ & ++ & ++ & + & ++ & +++ & +++ & ++ & ++ & + & ++ & ++ & ++ & ++ & ++ & + & ++ & ++ & +++ & + & + \\
\hline Cell clumping & $\begin{array}{ll}- \\
-\end{array}$ & - & - & $\begin{array}{ll}- \\
-\end{array}$ & $\begin{array}{ll}- \\
-\end{array}$ & - & ++ & ++ & + & - & - & - & ++ & ++ & $\begin{array}{ll}- \\
-\end{array}$ & - & - & - & ++ & ++ & + & $\begin{array}{ll}- \\
\end{array}$ & - & - \\
\hline Cell shrinkage & - & - & - & - & - & - & ++ & + & - & - & $\begin{array}{lll}- & & \end{array}$ & $\begin{array}{lll}- & & \end{array}$ & ++ & + & - & - & - & - & ++ & + & - & - & - & - \\
\hline Apoptosis [\%] & 2.0 & 3.0 & 2.5 & 2.5 & 1.5 & 2.0 & 2.0 & 1.5 & 3.5 & 2.0 & 3.0 & 6.0 & 5.5 & 11 & 3.5 & 4.0 & 5.5 & 3.5 & 6.0 & 3.0 & 3.5 & 7.0 & 5.5 & 3.5 \\
\hline $\begin{array}{c}\text { Cell death } \\
{[\%]}\end{array}$ & 7.0 & 9.0 & 6.0 & 4.5 & 4.5 & 5.0 & 8.0 & 7.0 & 8.0 & 2.0 & 4.0 & 6.0 & 3.5 & 3.5 & 5.5 & 6.5 & 6.0 & 5.0 & 8.0 & 7.0 & 5.5 & 6.5 & 5.5 & 5.0 \\
\hline $\begin{array}{l}\text { Mitochondrial } \\
\text { activity [\%] } \\
\text { WST-1 assay }\end{array}$ & 66 & 77 & 76 & 79 & 68 & 86 & 42 & 58 & 52 & 59 & 64 & 71 & 64 & 44 & 60 & 69 & 70 & 73 & 75 & 73 & 65 & 76 & 56 & 80 \\
\hline $\begin{array}{c}\text { LDH release } \\
{[\%]}\end{array}$ & 12 & 9 & 8 & 11 & 2 & 4 & 11 & 6 & 4 & 2 & 4 & 5 & 16 & 9 & 5 & 4 & 4 & 0,6 & 4 & 5 & 2 & 2 & 4 & 4 \\
\hline
\end{tabular}

(lack of agglomerates) and sufficient for cellular uptake (Table 1). MWCTNs uptaken by L929 cells were accumulated in the peripheral cytoplasm around the nuclei.

The L929 cells incubated with MWCNT-8 h particles (250-800 nm length) at the highest concentrations (50.0-100.0 $\mathrm{mgml}^{-1}$ ) demonstrate shrinkage, spherical shapes and formed clusters after 48-h incubation. At $50.0-100.0 \mu \mathrm{gml}^{-1}$ concentrations agglomerates were noticed with the higher tendency to form those structures than MWCNT-12 h. Nanoparticles were observed around the cells strongly associated with the membranes. At the highest concentrations uptaken MWCNTs were accumulated in cytoplasm (Table 1). At lower doses of NPs (3.125-12.5 $\left.\mu \mathrm{gml}^{-1}\right)$ morphology of L929 fibroblasts was similar to control cultures.

Exposure of L929 cells to MWCNT-4 h (250-1000 $\mathrm{nm}$ length) at concentration $50.0-100.0 \mathrm{\mu gml}^{-1}$ induced morphological changes. The L929 cells became spherical, the cellular shrinkage and clusters appeared. Nanoparticles were observed around the cells strongly associated with the membranes. At highest concentration of MWCNT-4 h was not stable, and many agglomerates were noticed. The tendency to form agglomerates was higher than that for MWCNT-12 h. Cellular uptake of MWCNT-4 $\mathrm{h}$ at concentration $50.0-100.0 \mu \mathrm{gml}^{-1}$ was insufficient. Internalized material was accumulated in the peripheral cytoplasm and formed small brownish intercellular aggregates. At lower doses of MWCNT-4 h $\left(3.125-12.5 \mu \mathrm{gml}^{-1}\right)$ nanomaterial was uptaken and located in peripheral cytoplasm.

The CNT control samples (200-5000 nm length) at concentrations from $50.0 \mu \mathrm{gml}^{-1}$ to $100.0 \mu \mathrm{gml}^{-1}$ were not stable in suspensions and many agglomerates were noticed. L929 cells displayed shrinkage, spherical shapes and formed clusters at 100.0, 50.0 and $25.0 \mu \mathrm{gml}^{-1}$ concentration (with lower cell internalization). At higher concentrations the control MWCNTs were observed around the cells strongly associated with the cell membranes. Nanomaterial was located in peripheral cytoplasm and formed small black intercellular aggregates.

The biocompatibility results show differences in mitochondrial activity of L929 mouse fibroblasts that depend on the length (chopped by ultrasounds for 4, $8,12 \mathrm{~h})$ and concentration $(0.0,3.125,6.25,12.5,25.0$, $50.0,100.0 \mu \mathrm{gml}^{-1}$ ) of the nanomaterial. Mitochondrial activity of L929 cells was presented in the Figure 7a.
Lower cytotoxicity was observed in cell cultures treated with the shortest carbon nanotubes (chopped for 12 $\mathrm{h}$, up to $400 \mathrm{~nm}$ length) at concentration $3.125 \mu \mathrm{gml}^{-1}$ and in the range between $12.5-50.0 \mu \mathrm{gml}^{-1}$. The cells incubated with carbon nanotubes at concentrations of $25.0 \mathrm{\mu gml}^{-1}$ demonstrate relatively high viability (76\%) and the relatively lower level of $\mathrm{LDH}$ release $(8.0 \%)$, and cell death $(6.0 \%)$. For the concentration $50.0 \mu \mathrm{gml}^{-1}$ of MWCNTs, the reduction of relative mitochondrial activity was not significant (77\%), but the LDH release and cell death were slightly higher $(9.0 \%$ for LDH and cell death). It might be due presence of aggregates that affect cell membrane integrity. The mitochondrial cell activity was the lowest at concentrations $100.0 \mu \mathrm{gml}^{-1}$ (the highest level of aggregates) $(\mathrm{p}<0.05)$ with the higher LDH release $(12.0 \%)$ and cell death level $(7.0 \%)$. The agglomeration also affected cells viability decreased to approximately $66 \%-86 \%$ vs. free grown cells (Figure 7a).

The MWCNTs chopped for $8 \mathrm{~h}$ (250-800 nm length) and $4 \mathrm{~h}(250-1000 \mathrm{~nm}$ length) (in Fig. 7b) at concentrations $100.0 \mu \mathrm{gml}^{-1}(\mathrm{p}<0.001)$ and $50.0 \mu \mathrm{gml}^{-1}(\mathrm{p}<0.005)$ significantly reduced cells activity (in the range between $42 \%$ to $58 \%$ for the MWCNTs- 8 h and $64 \%$ to $44 \%$ for the MWCNTs-4 h). The lower mitochondrial metabolism for the highest MWCNTs concentration might be related to agglomeration tendency of MWCNTS. Thus, presence of agglomerates evoke higher level of LDH leakage and cell death especially for MWCNTs chopped for $8 \mathrm{~h}$. The mitochondrial cell activity was reduced to approximately $59 \%(\mathrm{p}<0.005)$ at concentration $12.5 \mu \mathrm{gml}^{-1}$ for the MWCNTs- $8 \mathrm{~h}$ and $69 \%$ for the MWCNTs- $4 \mathrm{~h}$. The nanoparticles with lengths that range from 250 to $800 \mathrm{~nm}$ reduced cellular activity to $64 \%$ at concentration $6.25 \mu \mathrm{gml}^{-1}$ and $71 \%$ at concentration $3.125 \mu \mathrm{gml}$ ${ }^{-1}$. The MWCNTs-4 $\mathrm{h}$ at $6.25 \mu \mathrm{gml}^{-1}$ and $3.125 \mu \mathrm{gml}$ ${ }^{-1}$ concentrations reduced mitochondrial metabolism to $70 \%$ and $73 \%$, respectively. Control samples (200-5000 $\mathrm{nm}$ length) presented the lowest relative cell viability at concentration $6.25 \mu \mathrm{gml}^{-1}(\mathrm{p}<0.005)$ and $25.0 \mu \mathrm{gml}^{-1}$. For other control samples mitochondrial metabolism was found to be reduced in the range between $65 \%$ to $80 \%$, with the highest mitochondrial activity $(80 \%)$ for the concentration $3.125 \mu \mathrm{gml}^{-1}$.

The LDH released into cell culture medium is an indicator of irreversible cell death due to cell membrane damage $^{30}$. Results from the LDH leakage showed dose- 
Mouse fibroblast cells control
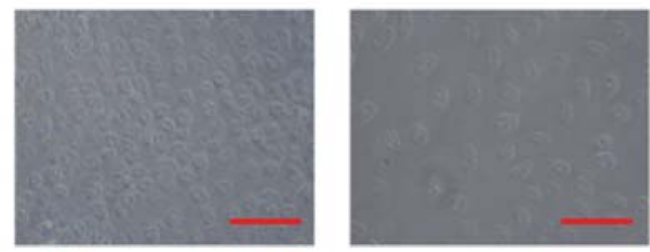

Nanomaterials concentration

$3.125 \mu \mathrm{g} / \mathrm{ml}$
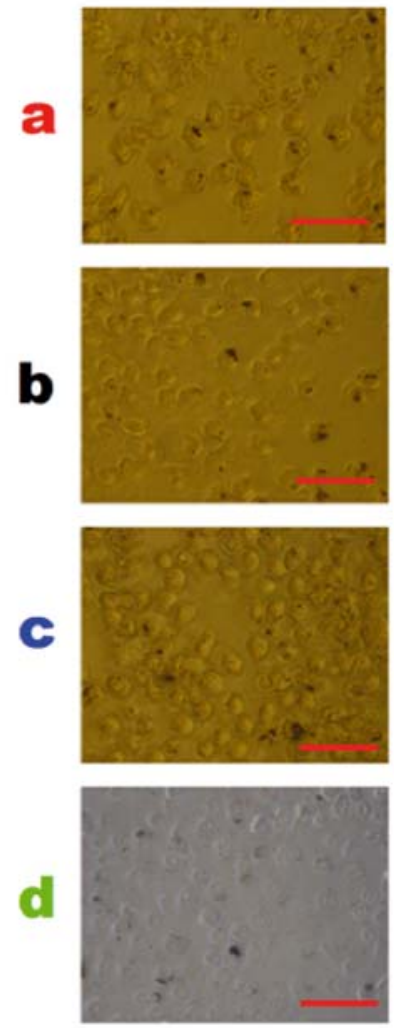

$25 \mu \mathrm{g} / \mathrm{ml}$
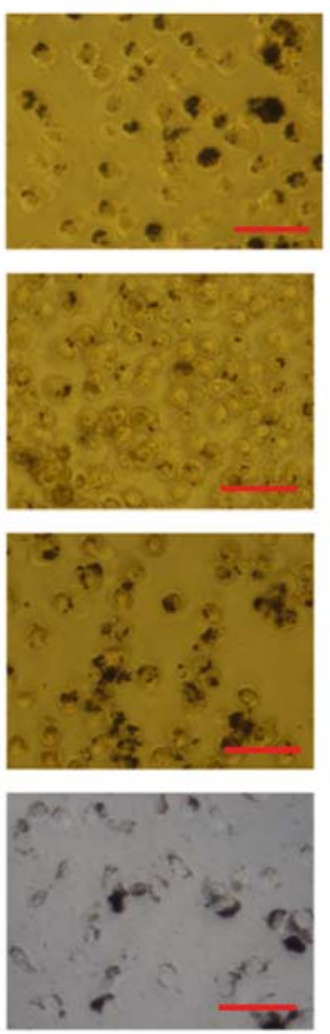

$50 \mu \mathrm{g} / \mathrm{ml}$
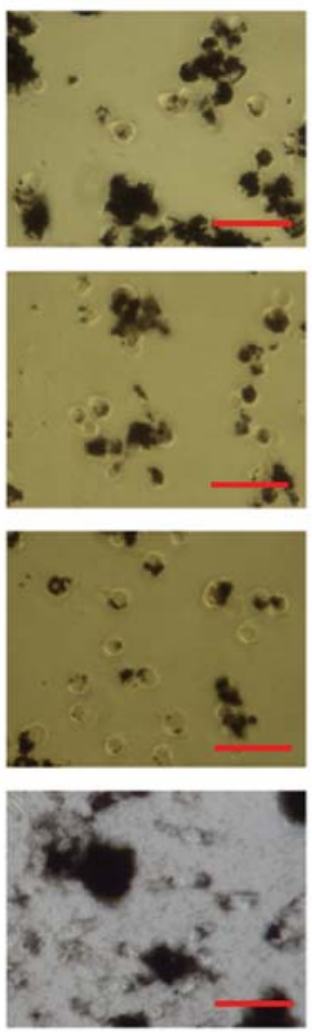

Figure 7. Mitochondrial activity and membrane integrity of L929 mouse fibroblast cells after 48-hour incubation with carbon nanotubes: control sample and after acids functionalization; chopped during 12-h sonication (a), $8 \mathrm{~h}$ (b), $4 \mathrm{~h}$ (c) sonication and control CNT (d). Bars represent standard deviation. Asterisk $\left(^{*}\right)$ indicates statistically significant differences $(* \mathrm{p}<0.05),(* * \mathrm{p}<0.01)$

-dependent cytotoxicity. In Fig. $7 b$ it can be seen that LDH release caused by most types of MWCNTs were below $15 \%$, excluded MWCNT-4 h samples at concentration $100.0 \mu \mathrm{gml}^{-1}$. The highest LDH leakage level was noticed for the MWCNT-12 $\mathrm{h}$ in concentration of $100.0 \mu \mathrm{gml}^{-1}$ and for the MWCNT-4 h of $100 \mu \mathrm{gml}^{-1}$ due to cytotoxicity of aggregates. The lowest membrane damage was noticed when L929 cells were incubated at concentration of $12.5 \mu \mathrm{gml}^{-1}$ with MWCNT-12 $\mathrm{h}$ and for the MWCNT-control at concentrations of 12.5 and 25.0 $\mu \mathrm{gml}^{-1}$. For MWCNT-8 h the lowest LDH leakage was noticed at concentration of $12.5 \mu \mathrm{gml}^{-1}$. The MWCNT-4 $\mathrm{h}$ showed the best biocompatibility at concentration of $3.125 \mu \mathrm{gml}^{-1}$.

Identification of apoptotic cells was evaluated using the Annexin V-Alexa Fluor $\AA^{\circledR} 488$ conjugate. The results of the Annexin V/PI assay demonstrated that the exposition to increasing concentrations (3.125-100.0 $\mu \mathrm{gml}^{-1}$ ) of MWCNTs did not show a concentration-dependent cell reaction (Figure 7c, 7d). The MWCNT-12 h and MWCNT-8 h incubation resulted in lower percentage of apoptotic than necrotic cells. The MWCNT-4 h induced lower rates of necrosis than apoptosis at concentrations
$100.00 \mu \mathrm{gml}^{-1}$ and $50.00 \mu \mathrm{gml}^{-1}$ and the control sample at concentration $12.5 \mu \mathrm{gml}^{-1}$.

Physicochemical properties of nanoparticles such as size, composition, concentration, shape, and surface (e.g. charge, coating, aspect ratio), as well as the cell type, all play crucial role in determining the predominant uptake pathway(s) and nanomaterial toxicity ${ }^{31-33}$. Thus, in our study the influence of carbon nanotubes with specific lengths on mitochondrial metabolism has been examined. The cells incubated with carbon nanotubes at the highest concentration of $100.0 \mu \mathrm{gml}^{-1}$ and 50.0 $\mu \mathrm{gml}^{-1}$ demonstrate viability in the range between 42 to $77 \%$ (Table 1). The suspensions of carbon nanotubes at concentrations from 50.0 to $100.0 \mu \mathrm{gml}^{-1}$ were not stable and many agglomerates were noticed. The concentration of MWCNTs up to the $25 \mu \mathrm{gml}^{-1}$ presents low tendency of formation agglomerates. On the basis of the obtained micrographs we can conclude that the most stable MWCNTs solution was recorded for 12.5 $\mu \mathrm{gml}^{-1}$. This tendency was observed for all the tested samples in the presented experiment excluding CNT control sample. Differences in particles dispersion and agglomeration have been shown to play important role 
in nanotoxicity ${ }^{31}$. It is known that NPs with large area have strong tendency to agglomerate in liquids (e.g. culture media) and interact with proteins in cell culture environment. This may lead to vary intracellular responses and may affect nanomaterials interaction with cellular membrane and cellular uptake ${ }^{34}$. It is also known that non-spherical geometry e.g. cylindrical such as MWCNTs may influence agglomeration, cellular uptake followed by cellular response ${ }^{\mathbf{3 1}}$.

It was already noticed before by Fraczek-Szczypta et al. $^{34}$ that the application of carbon nanotubes in biological environment is strongly limited due to the agglomeration problem $^{35}$. The strong tendency of all kinds of carbon nanotubes to create agglomerates is due to strong van der Waals interactions. The agglomerated carbon nanotubes have different properties than those observed for single, separated objects ${ }^{\mathbf{3 6}}$. Even good dispersion of nanomaterial before in vitro testing does not solve the problem of CNTs tendency to secondary aggregation ${ }^{\mathbf{3 4}}$. Those properties of carbon nanomaterial can directly inhibit cellular uptake mechanism and internalization. Difficulties of internalization were observed in many experiments, but no common conclusion was made ${ }^{32,37}$. Lam et al. $^{7}$ reported that MWCNTs have tendency to agglomerate into large particles (micrometer-order scale). It was also found that aggregates might affected cell viability and evoke cell membrane disruption.

Results from WST-1 assay for all tested samples suggest that at $100.0 \mu \mathrm{gml}^{-1}$ mitochondrial activity can be reduced because association of MWCNTs with the cellular membranes. Mitochondrial activity at lower concentrations was not reduced as much as cellular activity at higher concentrations. Some authors suggest that relatively low $\mathrm{LDH}$ leakage at high concentration of nanomaterials is caused by partially blocked leakage tunnels of cells by aggregates of CNTs at higher concentration ${ }^{\mathbf{3 6}, 38}$. Nagai et al. ${ }^{30}$ focused their attention on the diameter and rigidity of multiwalled carbon nanotubes as their critical factors. According to his results carbon nanotubes with high crystallinity shows tendency to penetrate the membrane cells and exhibits high cytotoxicity. As references Nagai et al. ${ }^{30}$ confirmed that carbon nanotubes with specific size and form can be less biologically reactive and more prone to biodegradation ${ }^{\mathbf{3 0}}$.

\section{CONCLUSIONS}

The chopping of the CNTs requires optimization in respect to the amount of generated oxygen containing functional groups and amorphous carbon during acids treatment in the assistance of ultrasounds. The highest biocompatibility and the lowest tendency for the secondary agglomeration were detected for the MWCNTs sonicated for 12 and 8 hours in the concentration dose up to $12.5 \mu \mathrm{gml}^{-1}$. The nanotubes obtained by the sonication for 12 and 8 hours are relatively short, the functional groups are clearly indicated, the number of defects in crystal structure is not significant, and the amount of amorphous carbon is limited. The results obtained with WST-1, LDH and Annexin V/PI assays suggest that the highest concentration of tested nanomaterials (100.0 $\mu \mathrm{gml}^{-1}$ ) might evoke higher LDH leakage and cell death due to presence of agglomerates especially for MWCNTs chopped for $8 \mathrm{~h}$.

\section{ACKNOWLEDGEMENTS}

Authors are grateful for financial support from the National Science Center Poland within the OPUS Programme, number 2011/03/B/ST5/03239. We wish to express our thanks to Malgorzata Jedrzejczak from the West Pomeranian University of Technology in Szczecin, for the assistance in laboratory work.

\section{LITERATURE CITED}

1. Iijima, S. (1991). Helical microtubules of graphitic carbon. Nature, 354, 56-58. DOI: 10.1038/354056a0.

2. Donaldson, K., Aitken, R., Tran, L., Stone, V., Duffin, R., Forrest, G. \& Alexander, A. (2006). Carbon nanotubes: a review of their properties in relation to pulmonary toxicology and workplace safety. Toxicol. Sci. 92, 5-22. DOI: 10.1093/ toxsci/kfj130.

3. Chen, X., Chen, H., Tripisciano, C., Jedrzejewska, A., Rümmeli, H.M., Klingeler, R., Chu, P.K. \& Borowiak-Palen, E. (2011). Carbon-nanotube-based stimuli-responsive controlledrelease system. Chem. Eur. J. 17, 4454-4459. DOI: 10.1002/ chem.201003355.

4. Kumar, A.P., Hul, Y., Yamamoto, Y., Hoe, N.B., Wie, T.S., Mu, D., Sun, Y., Joo, L.S., Dagher, R., Zielonka, L.M., Wang, D.Y., Lim, B., Chow, V.T., Crum, C.P., Xian, W. \& McKeon, F. (2011). Distal airway stem cells yield alveoli in vitro and during lung regeneration following H1N1 influenza infection. Cell, 147, 525-538. DOI: 10.1016/j.cell.2011.10.001.

5. Meng, L., Zhang, X., Lu, Q., Fei, Z. \& Dyson, P.J. (2012). Single walled carbon nanotubes as drug delivery vehicles: targeting doxorubicin to tumors. Biomaterials, 33, 1689-1698. DOI: 10.1016/j.biomaterials.2011.11.004.

6. Lacerda, L., Bianco, A., Prato, M. \& Kostarelos, K. (2006). Carbon nanotubes as nanomedicines: from toxicology to pharmacology. Adv. Drug Delivery Rev. 58, 1460-1470. DOI: 10.1016/j.addr.2006.09.015.

7. Lam, C.W., James, J.T., McCluskey, R., Arepalli, S. \& Hunter, R.L. (2006). A review of carbon nanotube toxicity and assessment of potential occupational and environmental health risks. Rev. Toxicol. 36, 189-217. DOI: 10.1080/10408440600570233.

8. Markovic, M.Z., Harhaji-Trajkovic, L.M., Todorovic-Markovic, B.M., Kepić, D.P., Arsikin, K.M., Jovanović, S.P., Pantovic, A.C., Dramićanin, M.D. \& Trajkovic, V.S. (2011). In vitro comparison of the photothermal anticancer activity of graphene nanoparticles and carbon nanotubes. Biomaterials, 32, 1121-1129. DOI: 10.1016/j.biomaterials.2010.10.030.

9. Sahithi, K., Swetha, M., Ramasamy, K., Srinivasan, N. \& Selvamurugan, N. (2010). Polymeric composites containing carbon nanotubes for bone tissue engineering. Int. J. Biol. Macromol. 46, 281-283. DOI: 10.1016/j.ijbiomac.2010.01.006.

10. Elgrabli, D., Abella-Gallart, S., Robidel, F., Rogerieux, F., Boczkowski, J. \& Lacroix, G. (2008). Induction of apoptosis and absence of inflammation in rat lung after intratracheal instillation of multiwalled carbon nanotubes. Toxicology, 253, 131-136. DOI: 10.1016/j.tox.2008.09.004.

11. De Nicola, M., Gattia, D.M., Bellucci, S., Bellis, G.D., Micciulla, F., Pastore, R., Tiberia, A., Cerella, C., D'Alessio, M., Antisari, M.V., Marazzi, R., Traversa, E., Magrini, A., Bergamaschi, A. \& Ghibelli, L. (2007). Effect of different carbon nanotubes on cell viability and proliferation. J. Phys: Condens. Matter. 19, 395013-395020. DOI: 10.1088/09538984/19/39/395013.

12. Cui, D., Tian, F.C.S., Wang, M. \& Gao, H. (2005). Effect of single-wall carbon nanotubes on human HEK293 cells. Toxicol. Lett. 155, 73-85. DOI: 10.1016/j.toxlet.2004.08.015. 
13. Suh, W.H., Suslick, K.S., Stucky, G.D. \& Suh, Y.H. (2009). Nanotechnology, nanotoxicology, and neuroscience. Prog. Neurobiol. 87, 133-170. DOI: 10.1016/j.pneurobio.2008.09.009.

14. Wang, X., Podila, R., Shannahan, J.H., Rao, A.M. \& Brown, J.M. (2011). Intravenously delivered graphene nanosheets and multiwalled carbon nanotubes induce site-specific Th2 inflammatory responses via the IL-33/ST2 axis. Chem. Res. Toxicol. 24, 2028-2039. DOI: 10.2147/IJN.S44211.

15. Bekyarova, E., Haddon, R.C. \& Parpura, V. (2007). Biofunctionalization of carbon nanotubes. NTLS. DOI:10.1002/9783527610419.ntls0002.

16. Kagan, V.E., Konduru, N.V., Feng, W., Allen, B.L., Conroy, J., Volkov, Y., Vlasova, I.I., Belikova, N.A., Yanamala, N., Kapralov, A., Tyurina, Y.Y., Shi, J., Kisin, E.R., Murray, A.R., Franks, J., Stolz, D., Gou, P., Klein-Seetharaman, J., Fadeel, B., Star, A. \& Shvedova, A.A. (2010). Carbon nanotubes degraded by neutrophil myeloperoxidase induce less pulmonary inflammation. Nature Nanotech. 5, 354-359. DOI: 10.1038/nnano.2010.44

17. Li, J.Z. \& Zhang, Y.F. (2006). Cutting of multi walled carbon nanotubes. Appl. Surf. Sci. 252, 2944-2948. DOI: 10.1016/j.apsusc.2005.04.039.

18. Peng, J., Qu, X.X., Wei, G.S., Li, J.Q. \& Qiao, J.L. (2004). The cutting of MWNTs using gamma radiation in the presence of dilute sulfuric acid. Carbon, 42, 2741-2744. DOI: 10.1016/j.carbon.2004.05.015.

19. Gu, Z., Peng, H., Hauge, R.H., Smalley, R.E. \& Margrave, J.L. (2002). Cutting single-wall carbon nanotubes through fluorination. Nano Lett. 2, 1009-1013. DOI: 10.1021/nl025675+.

20. Wang, X.X., Wang, J.N., Su, L.F. \& Niu, J.J. (2006). Cutting of multi-walled carbon nanotubes by solid-state reaction. J. Mater. Chem. 16, 4231-4234. DOI: 10.1039/B609231D.

21. Pierard, N., Fonseca, A., Konya, Z., Willems, I., Tendeloo, G.V. \& Nagy, J.B. (2001). Production of short carbon nanotubes with open tips by ball milling. Chem. Phys. Lett. 335, 1-8. DOI: 10.1016/S0009-2614(01)00004-5.

22. Konya, Z., Vesselenyi, I., Niesz, K., Kukovecz, A., Demortier, A., Fonseca, A., Delhalle, J., Mekhalif, Z., Nagy, J.B., Koos, A.A., Osváth, Z., Kocsonya, A., Biró, L.P. \& Kiricsi, I. (2002). Large scale production of short functionalized carbon nanotubes. Chem. Phys. Lett. 360, 429-435. DOI: 10.1016/ S0009-2614(02)00900-4.

23. Kukovecz, K., Kanyo, T., Konya, Z. \& Kiricsi, I. (2005). Long-time low impact ball milling of multi-wall carbon nanotubes. Carbon, 43, 994-1000. DOI: 10.1016/j.carbon.2004.11.030.

24. Koshio, A., Yudasaka, M., Zhang, M. \& Iijima, S. (2001). A simple way to chemically react single-wall carbon nanotubes with organic materials using ultrasonication. Nano Lett. 1, 361-363. DOI: 10.1021/n10155431.

25. Shimada, T., Yanase, H., Morishita, K., Hayashi, J.I. \& Chiba, T. (2004). Points of onset of gasification in a multi-walled carbon nanotube having an imperfect structure. Carbon, 42, 1635-1639. DOI: 10.1016/j.carbon.2004.02.019.

26. Li, Q.W., Yan, H., Ye, Y.C., Zhang, J. \& Liu, Z.F. (2002). Defect location of individual single-walled carbon nanotubes with a thermal oxidation strategy. J. Phys. Chem. B. 106, 11085-8. DOI: 10.1021/jp026512c.

27. Kirk, J., Ziegler, K.J., Gu, Z., Shaver, J., Chen, Z., Flor, E.L., Schmidt, D.J., Chan, C., Hauge, R.H. \& Smalley, R.E. (2005). Cutting single-walled carbon nanotubes. Nanotechnology, 16: S539-S544. DOI: 10.1088/0957-4484/16/7/031.

28. Wang, C., Guo, S., Pan, X., Chen, W. \& Bao, X. (2008). Tailored cutting of carbon nanotubes and controlled dispersion of metal nanoparticles inside their channels. J. Mater. Chem. 18, 5782-5786. DOI: 10.1039/B811560E.

29. Hennrich, F., Krupke, R., Arnold, K., Stu1tz, J.A.R., Lebedkin, S., Koch, T., Schimmel, T. \& Kappes, M.M. (2007). The mechanism of cavitations-induced scission of single-walled carbon nanotubes. J. Phys. Chem. B. 111, 1932-1937. DOI: 10.1021/jp065262n.

30. Cheng, Q., Debnath, S., Gregan, E. \& Byrne, H.J. (2010). Ultrasound-assisted SWNTs dispersion: effects of sonication parameters and solvent properties. J. Phys. Chem. C. 114, 8821-8827. DOI: 10.1021/jp101431h.

31. Nagai, H., Okazaki, Y., Chew, S.H., Misawa, N., Yamashita, Y., Akatsuka, S., Ishihara, T., Yamashita, K., Yoshikawa, Y., Yasui, H., Jiang, L., Ohara, H., Takahashi, T., Ichihara, G., Kostarelos, K., Miyata, Y., Shinohara, H. \& Toyokuni, S. (2011). Diameter and rigidity of multiwalled carbon nanotubes are critical factors in mesothelial injury and carcinogenesis. Proc. Natl. Acad. Sci. USA 108, E1330-E1338. DOI: 10.1073/ pnas.1110013108.

32. Sohaebuddin, S.K., Thevenot, P.T., Baker, D., Eaton, J.W. \& Tang, L. (2010). Nanomaterial cytotoxicity is composition, size and cell type dependent. Part Fibre Toxicol. 7, 22. DOI: 10.1186/1743-8977-7-22.

33. Stern, S.T., Adiseshaiah, P.P. \& Crist, R.M. (2012). Autophagy and lysosomal dysfunction as emerging mechanisms of nanomaterials toxicity. Part Fibre Toxicol. 9, 20. DOI: 10.1186/1743-8977-9-20.

34. Gratton, S.E., Rapp, P.A., Pohlhaus, P.D., Luft, J.C., Madden, V.J., Napier, M.E. \& DeSimone, J.M. (2008). The effect of particle design on cellular internalization pathways. Proc. Natl. Acad. Sci. USA 105, 11613-11618. doi: 10.1073/ pnas.0801763105.

35. Fraczek-Szczypta, A., Menaszek, E. \& Blazewicz, S. (2011). Some observations on carbon nanotubes susceptibility to cell phagocytosis. J. Nanomater. 473516-473524. DOI: org $/ 10.1155 / 2011 / 473516$.

36. Wick, P., Manser, P., Limbach, L.K., Dettlaff-Weglikowska, U., Krumeich, F., Roth, S., Stark, W.J. \& Bruinink, A. (2007). The degree and kind of agglomeration affect carbon nanotube cytotoxicity. Toxicol. Lett. 168, 121-131. DOI: 10.1016/j.toxlet.2006.08.019.

37. Fotakis, G. \& Timbrell, J.A. (2006). In vitro cytotoxicity assays: Comparison of LDH, neutral red, MTT and protein assay in hepatoma cell lies following exposure to cadmium chloride. Toxicol. Lett. 160, 171-177. DOI: 10.1016/j.toxlet.2005.07.001.

38. Davoren, M., Herzog, E., Casey, A., Cottineau, B. \& Chambers, G. (2007). In vitro toxicity evaluation of single walled carbon nanotubes on human A549 lung cells. Toxicol. In Vitro. 21, 438-448. DOI: 10.1016/j.tiv.2006.10.007. 